\title{
ASSESSING THE SPECIFIC FACTORS OF EXERCISE CAPACITY IN PERFORMANCE JUDO
}

\author{
Laurențiu BOCIOAC $\breve{A}^{1 *}$ \\ ${ }^{1}$ National University of Physical Education and Sport, Faculty of Physical Education and Sport, \\ Bucharest, Romania \\ *Corresponding author: laurbocioaca@yahoo.com
}

https://doi.org/10.35189/dpeskj.2020.59.s.9

\begin{abstract}
A relatively young Olympic discipline, judo is characterised by spectacularity, combative spirit and complexity in the execution of specific techniques. The technical training model and reaching the sports shape are the main objectives in the preparation of performance judo athletes. Maximal and supramaximal demands in modern competitions, which are determined by the specific biomechanics of technical actions, require the adaptation of athletes to supramaximal effort and the continuous increase of their exercise capacity. This paper aims to determine the relationship between the specific factors of aerobic and anaerobic exercise capacity in senior performance judo athletes participating in national and international competitions. The research subjects are performance and high-performance male and female athletes aged 19 to 21 years, members of the Romanian Judo Federation. To conduct the research, general and specific methods of assessing and developing aerobic and anaerobic exercise capacity are used. The assessment of subjects in the three training mesocycles was based on lactacidaemia, glycaemia and laboratory spectrophotometry as methods of determining their anaerobic adaptation. To assess their specific anaerobic capacity, methods of determining blood lactate and laboratory spectrophotometry are used. Aerobic capacity is determined by spirometry and digitised pulse oximetry methods. Maximum oxygen consumption, blood haemoglobin and pulse oxygen levels are graphically represented and interpreted, together with the comparative calorimetric and thermographic assessment of the tested subjects. The research findings highlight the importance of assessing aerobic and anaerobic exercise capacity in the training of performance judo athletes through modern assessment and analysis methods.
\end{abstract}

Keywords: judo, performance, assessment, training, aerobic and anaerobic capacity.

\section{Introduction}

Studies conducted by most authors demonstrate the growing importance of performance capacity for judo athletes as a key factor in reaching maximum levels of competitive performance and adaptation (Abernethy et al., 1990). Since its establishment as an Olympic discipline, judo has undergone numerous changes in competition regulations and organization, which has required judo athletes to permanently adapt to different technical, tactical and psychomotor demands.

Compared to other sports disciplines, judo is characterised by highly stressful and intense motor acts and actions performed both during training and competition, which involve the execution of powerful techniques with complex biomechanics, extremely difficult strangles and leg-dislocation techniques, as well as a high level of physical and psychomotor adaptation. The high level of adaptation and performance is the consequence of a constant increase in aerobic and anaerobic exercise capacity, but also of permanently improved control and assessment methods (Murărețu et al., 2016). 
The relationship between aerobic and anaerobic exercise capacity within the structure of judo-specific demands is considered a major theme in the training process due to the importance of volume and intensity as fundamental factors of training, the relevance of the researched topic being highlighted by numerous authors who place different emphasis on the two types of adaptive capacity for judo athletes.

Thus, Farzaneh Hesari et al. (2014) consider that exercise capacity and maximum oxygen consumption are decisive in achieving maximum adaptation to specific effort. Changes produced in the technical and tactical structure of the fight as a result of permanent changes in competition requirements have led to modifying the relationship between volume and intensity, given that the pace of combat actions is constantly increasing. Due to the increased intensity of combat actions, important adaptations have occurred in the neuromuscular and circulatory systems of judo athletes.

Our research aims to highlight the adaptive changes induced by the specific effort, as well as the dynamics of the relationship between aerobic and anaerobic exercise capacity. The research purpose is to objectify the dynamic relationship between the adaptation to both aerobic and anaerobic exercise in conditions as close as possible to the competitive ones. Objectifying the adaptive dynamics of specific effort indicators allows optimal scheduling and planning of the training and competition. The competitive effort in judo as a combat discipline is highly demanding for athletes. Their permanent adaptation to these demands requires maximum anaerobic capacity and high aerobic capacity, according to Norman (2015). Such adaptations are the result of a training process using specific means and methods of assessment.

The research question - high-intensity effort during the combat rounds leads to adaptations related to an increase in oxygen saturation and maximum oxygen consumption?

Increasing specific adaptation is a permanent goal of research in elite judo (Schumann \& Rønnestad, 2019). Several studies show that it is important to determine both anaerobic alactic and lactic exercise capacity and aerobic capacity in top judo athletes (Sale et al., 1990). Determining the exercise capacity of performance judo athletes in laboratory conditions as close as possible to the competitive ones allows to increase the efficiency of training and avoid errors in selecting the means of training corresponding to judo demands (Artioli et al., 2012).

Assessing the exercise capacity in judo involves motor actions based on the execution of techniques with complex biomechanics and specific equipment, which require the use of appropriate methods and means of assessment and control (Franchini et al., 2013). The relationship between aerobic and anaerobic exercise capacity is largely influenced by the glycolytic capacity of the subject.

Anaerobic exercise capacity was assessed by determining the amount of blood lactate or lactacidaemia, namely the concentration of lactic acid in the blood (LA, mmol/L), and the spectrophotometric method was used as a comparative laboratory method (Schumann \& Rønnestad, 2019). For aerobic capacity, the comparative data obtained by spirometry are presented, considering that the main indicator is to determine forced vital capacity (FVC) and VO2max, as well as the evolution of digitised pulse oximetry (SPO2) and haemoglobin $(\mathrm{g} / \mathrm{dL})$. Aerobic capacity is determined by digitised pulse oximetry and spirometry during two 
stages, the initial and final ones, throughout the 6-month period of centralised athletic training.

The research is focused on establishing the relationship between anaerobic and aerobic capacity indicators as an effect of specific demands in performance judo. Data regarding the comparative analysis of exercise capacity were determined either directly (SPO2, VO2) or indirectly (FVC, LA, haemoglobin) during the execution of combat actions, but also during the training specific to the competitive judo activity (Imamura et al., 2007).

Permanent changes in the dynamic relationship between anaerobic and aerobic exercise capacity allow, through the values recorded for the specific indicators, to correctly calibrate the training load and optimally plan the intensity and volume of training. It is thus achieved an adapted assessment of exercise capacity in relation to the specific competitive model. Basic changes occurring in the structure of demands characteristic of elite judo competitions involve adjustments to the anaerobic lactic exercise (Hantău \& Bocioacă, 1998).

The current paper provides data gathered throughout a training macrocycle from 20 male and female senior athletes aged between 19 and 21 years, in different weight divisions, of international and national levels, authorised by the Romanian Judo Federation. Data regarding the indicators of aerobic and anaerobic exercise capacity, as well as the indicators of overall exercise capacity, were made available to us by the Romanian Judo Federation and the UNEFS Sports Club (where the author works as a coach and teacher), which facilitated the development of the current research.

\section{Methodology}

Each sports discipline has its own characteristics and specificities. The analysis of specific requirements in terms of both conditional/coordination motor skills and necessary adaptive abilities is an issue of utmost importance in the development and design of intervention directions, but also in the selection of methods, means and equipment needed to conduct a research. The methods used to explore the adaptive abilities of judo athletes are different, depending on each author's background. Thus, studies present data and assessment methods for adaptive physical, biochemical or psychomotor indicators. Numerous authors emphasise the relationship between different biochemical indicators and the athlete's ability to develop a maximum level of motor skills.

In order to determine the dynamic relationship between the specific factors of exercise capacity, an initial assessment was performed at the start of the training macrocycle, and then at the end of it, after a time interval corresponding to both the activity and the domestic and international competitive calendars. The method used for anaerobic capacity, which is characterised by high-intensity effort and lactic acid accumulation (Franchini et al., 2013), consisted in determining lactacidaemia by establishing the concentration of lactic acid in the blood (LA, mmol/L), as well as haemoglobin (g/dL) levels. Most specialists consider lactacidaemia as an important indicator of exercise intensity and a factor of adaptation to anaerobic exercise.

According to studies on the specific effort in judo, the average length of the competitive effort is related to the statutory duration, namely 5 minutes at the most. As previously mentioned, given that the effort is very intense during a judo combat and the rest times are 
not sufficiently long, oxidative ATP re-synthesis is not possible, and therefore the effort becomes dependent on the glycolytic pathway.

During a competition, an athlete can participate in three combat rounds on average, the duration of the statutory break being equal to the duration of the fight (Franchini et al., 2018). According to these data, judo effort falls into the category of anaerobic lactic exercise. Lactic acid was determined after three combat rounds with a duration of 5 minutes and a break of 5 minutes in order to obtain the specific fight-intensity demand, thus respecting the characteristics of the competitive demand from the viewpoint of the bouts of effort (Norman, 2015). Aerobic capacity was assessed by the computerised spirometry test in order to determine forced vital capacity (FVC) through "the volume of air that can forcibly be blown out after full inspiration" (Perez, 2013) and indirectly calculate maximum oxygen consumption (VO2 max). The volume-intensity relationship during the specific effort was measured using digitised pulse oximetry ( $\mathrm{SpO} 2)$ to determine blood oxyhaemoglobin saturation (Beneke et al., 2002). Due to the inter-conditional relationship, the results of the two tests (for forced vital capacity and maximum oxygen consumption) were presented as average values for the two indicators.

Statistical data processing for both tests was performed through the calculation of the arithmetic mean (X), standard deviation (STDEVP) and variation (VARP). The results are graphically represented in Tables 1-3 and Figures 1-5. Oxygen saturation data were collected after each combat round at the end of the 5-minute effort, in the standing position to avoid variations caused by compliance with specific combat conditions, with the help of a digital pulse oximeter, Sanitas model, type SPO25. Haemoglobin samples were collected through the calorimetric EDTA method, the Sysmex XT4000i version that "uses the power of fluorescent flow cytometry and hydrodynamic focusing technologies" (MYCO Instrumentation, Inc. 2014), at the beginning and the end of the training period, concurrently with the regular medical check.

\section{Results}

Table 1. Initial and final data for aerobic capacity - Spirometry $(F V C)$ and digitised pulse oximetry (SpO2) tests

\begin{tabular}{lcccc}
\hline $\begin{array}{c}\text { Name } \\
\text { initials }\end{array}$ & $\begin{array}{c}\text { Female/ } \\
\text { Male }\end{array}$ & $\begin{array}{c}\text { Weight class } \\
(\mathrm{kg})\end{array}$ & $\begin{array}{c}\text { Initial spirometry and } \\
\text { pulse oximetry tests } \\
(\text { FVC/SpO2) }\end{array}$ & $\begin{array}{c}\text { Final spirometry and pulse } \\
\text { oximetry tests (FVC/SpO2) }\end{array}$ \\
\hline M.L. & $\mathrm{F}$ & 52 & 97 & 98 \\
C.B. & $\mathrm{M}$ & 73 & 94 & 98 \\
I.N. & $\mathrm{F}$ & 78 & 90 & 99 \\
N.A. & $\mathrm{F}$ & 52 & 90 & 97 \\
C.C. & $\mathrm{F}$ & 48 & 97 & 97 \\
M.A. & $\mathrm{M}$ & 95 & 92 & 94 \\
C.A. & $\mathrm{F}$ & 48 & 94 & 94 \\
C.M. & $\mathrm{F}$ & 48 & 92 & 99 \\
L.A. & $\mathrm{M}$ & 66 & 97 & 99 \\
O.A. & $\mathrm{F}$ & 52 & 96 & 99
\end{tabular}




\begin{tabular}{lcccc} 
P.A. & M & 73 & 90 & 97 \\
S.N. & F & 52 & 97 & 99 \\
B.C. & M & 81 & 92 & 99 \\
D.V. & M & 66 & 97 & 97 \\
C.E. & F & 57 & 98 & 98 \\
S.C. & F & 52 & 94 & 97 \\
D.R. & F & 52 & 92 & 97 \\
D.S. & M & 73 & 93 & 99 \\
V.I. & M & 100 & 96 & 97 \\
A.D. & $M$ & 100 & 99 & 99 \\
& & AVERAGE & 93.1 & 97.4 \\
& & STDVP & 2.7 & 1.4 \\
& & VARP & 7.8 & 2.2 \\
\hline
\end{tabular}

Table 1 shows the results obtained in the initial and final tests for forced vital capacity (FVC) and blood oxygen saturation - pulse oximetry, corresponding to the values recorded by each athlete per gender and weight class in which the subject participates, as well as to the values of statistical indicators.

Table 2. Evolution of data recorded in the initial and final tests for the specific indicators of aerobic capacity, maximum oxygen consumption (VO2 max) and haemoglobin ( $g / d L)$

\begin{tabular}{lcccccc}
\hline $\begin{array}{c}\text { Name } \\
\text { initials }\end{array}$ & $\begin{array}{c}\text { Female/ } \\
\text { Male }\end{array}$ & $\begin{array}{c}\text { Weight } \\
\text { class (kg) }\end{array}$ & $\begin{array}{c}\text { Initial } \\
\text { VO2 test }\end{array}$ & $\begin{array}{c}\text { Final } \\
\text { VO2 test }\end{array}$ & $\begin{array}{c}\text { Initial } \\
\text { haemoglobin } \\
\text { (g/dL) test }\end{array}$ & $\begin{array}{c}\text { Final } \\
\text { haemoglobin } \\
\text { (g/dL) test }\end{array}$ \\
\hline M.L. & $\mathrm{F}$ & 52 & 28 & 40 & 11.3 & 12.8 \\
C.B. & $\mathrm{M}$ & 73 & 28 & 40 & 12.6 & 13.5 \\
I.N. & $\mathrm{F}$ & 78 & 40 & 43 & 11.7 & 13.3 \\
N.A. & $\mathrm{F}$ & 52 & 36 & 40 & 12.4 & 12.7 \\
C.C. & $\mathrm{F}$ & 48 & 36 & 42 & 16.0 & 15.8 \\
M.A. & $\mathrm{M}$ & 95 & 30 & 45 & 11.8 & 11.8 \\
C.A. & $\mathrm{F}$ & 48 & 32 & 35 & 12.1 & 12.5 \\
C.M. & $\mathrm{F}$ & 48 & 30 & 33 & 12.4 & 13.3 \\
L.A. & $\mathrm{M}$ & 66 & 33 & 37 & 13.3 & 13.6 \\
O.A. & $\mathrm{F}$ & 52 & 28 & 33 & 12.8 & 13.7 \\
P.A. & $\mathrm{M}$ & 73 & 30 & 34 & 14.6 & 15.3 \\
S.N. & $\mathrm{F}$ & 52 & 33 & 36 & 14.6 & 15.1 \\
B.C. & $\mathrm{M}$ & 81 & 35 & 38 & 15.7 & 15.8 \\
D.V. & $\mathrm{M}$ & 66 & 30 & 34 & 15.2 & 15.9 \\
C.E. & $\mathrm{F}$ & 57 & 33 & 35 & 13.3 & 13.6 \\
S.C. & $\mathrm{F}$ & 52 & 31 & 33 & 12.5 & 14.5 \\
D.R. & $\mathrm{F}$ & 52 & 35 & 40 & 14.2 & 15.3 \\
D.S. & $\mathrm{M}$ & 73 & 37 & 43 & 14.6 & 15.8 \\
V.I. & $\mathrm{M}$ & 100 & 43 & 45 & 11.9 & 14.7 \\
A.D. & $\mathrm{M}$ & 100 & 41 & 43 & 16.0 & 16.1 \\
& & AVERAGE & 33.4 & 38.4 & 13.4 & 14.2 \\
& & STDEVP & 4.2 & 4 & 2.9 & 3 \\
& & VARP & 18.3 & 16.5 & 12.6 & 13.7 \\
\hline
\end{tabular}


Table 2 shows the values recorded by the research subjects in the initial and final tests for blood haemoglobin levels, as well as the values of statistical indicators

Table 3. Evolution of data recorded in the initial and final tests for the specific indicators of lactic exercise capacity ( $L A, \mathrm{mmol} / \mathrm{L})$

\begin{tabular}{lcccc}
\hline $\begin{array}{c}\text { Name } \\
\text { initials }\end{array}$ & $\begin{array}{c}\text { Female/ } \\
\text { Male }\end{array}$ & $\begin{array}{c}\text { Weight class } \\
(\mathrm{kg})\end{array}$ & $\begin{array}{c}\text { Initial LA } \\
(\mathrm{mmol} / \mathrm{L})\end{array}$ & $\begin{array}{c}\text { Final LA } \\
(\mathrm{mmol} / \mathrm{L})\end{array}$ \\
\hline M.L. & $\mathrm{F}$ & 52 & 12.51 & 14.32 \\
C.B. & $\mathrm{M}$ & 73 & 12.54 & 13.55 \\
I.N. & $\mathrm{F}$ & 78 & 11.18 & 12.41 \\
N.A. & $\mathrm{F}$ & 52 & 10.32 & 12.15 \\
C.C. & $\mathrm{F}$ & 48 & 13.45 & 16.18 \\
M.A. & $\mathrm{M}$ & 95 & 12.15 & 17.4 \\
C.A. & $\mathrm{F}$ & 48 & 12.26 & 14.18 \\
C.M. & $\mathrm{F}$ & 48 & 14.64 & 15.16 \\
L.A. & $\mathrm{M}$ & 66 & 10.27 & 17.41 \\
O.A. & $\mathrm{F}$ & 52 & 11.52 & 16.45 \\
P.A. & $\mathrm{M}$ & 73 & 14.51 & 16.5 \\
S.N. & $\mathrm{F}$ & 52 & 12.45 & 17.51 \\
B.C. & $\mathrm{M}$ & 81 & 12.23 & 13.78 \\
D.V. & $\mathrm{M}$ & 66 & 11.57 & 12.81 \\
C.E. & $\mathrm{F}$ & 57 & 14.52 & 16.23 \\
S.C. & $\mathrm{F}$ & 52 & 14.32 & 17.42 \\
D.R. & $\mathrm{F}$ & 52 & 14.46 & 15.18 \\
D.S. & $\mathrm{M}$ & 73 & 13.43 & 17.14 \\
V.I. & $\mathrm{M}$ & 100 & 14.68 & 17.12 \\
A.D. & $\mathrm{M}$ & 100 & 15.36 & 16.42 \\
& & AVERAGE & 13.2 & 15.8 \\
& & STDVP & 1.8 & 1.9 \\
& & VARP & 9 & 12.0 \\
\hline
\end{tabular}

Table 3 shows the values recorded for the specific indicator of adaptation to anaerobic effort, namely lactic acid, as well as the values of statistical indicators corresponding to the weight class of the tested subjects.

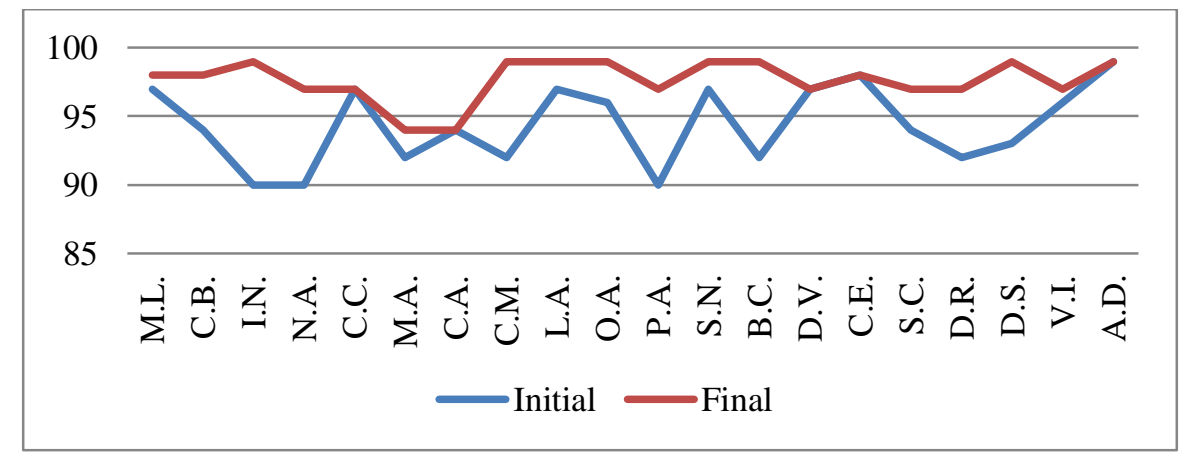

Figure 1. Initial and final data for aerobic capacity - Digitised pulse oximetry (SpO2) tests 
Figure 1 shows the dynamic evolution of the results obtained in the initial and final tests for the specific indicator of adaptive aerobic capacity, namely blood oxygen saturation digitised pulse oximetry.

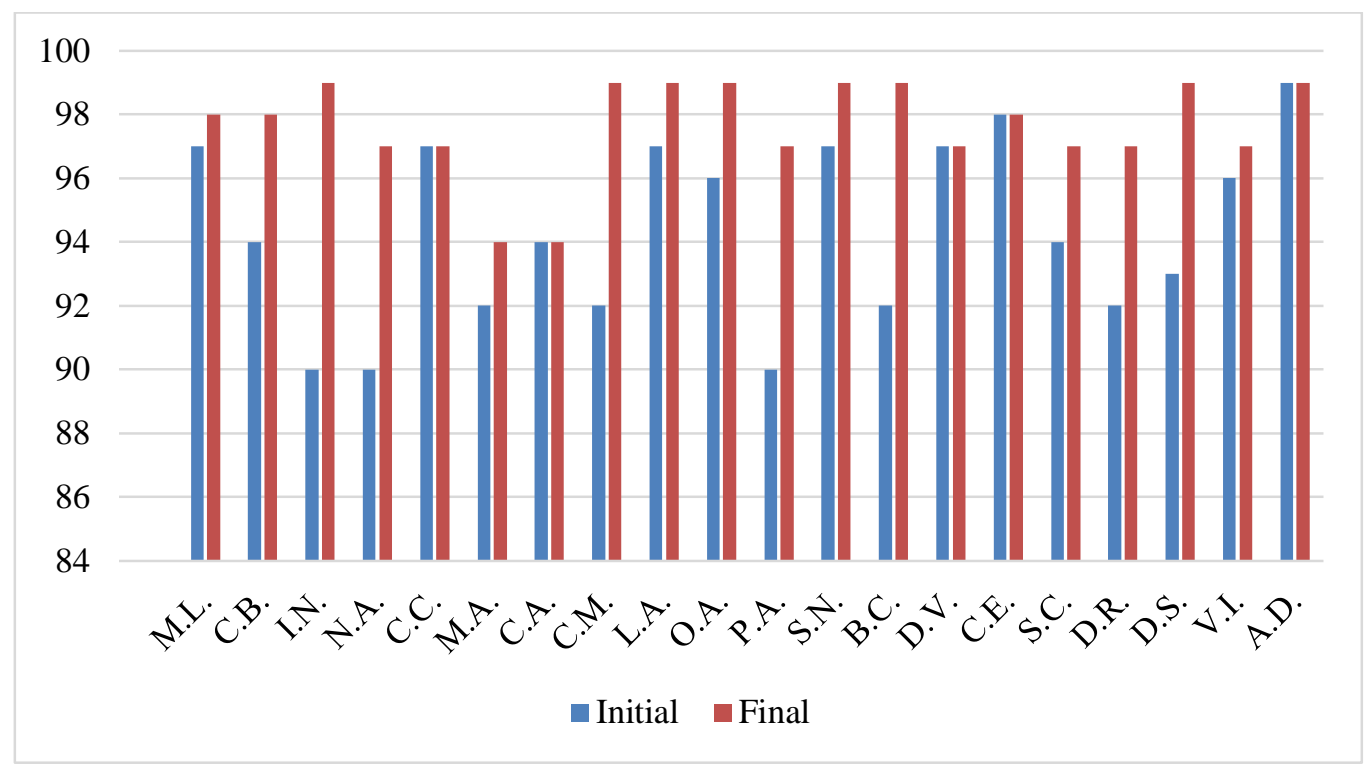

Figure 2. Initial and final data for aerobic capacity - Spirometry (FVC) and digitised pulse oximetry $(\mathrm{SpO} 2)$ tests

Figure 2 shows the comparative values recorded in the initial and final tests using computerised spirometry and digitised pulse oximetry. An increase in oxygen saturation was noted at the end of the research, with a dynamic that was very close to the evolution of haemoglobin, the two factors being inter-conditional.

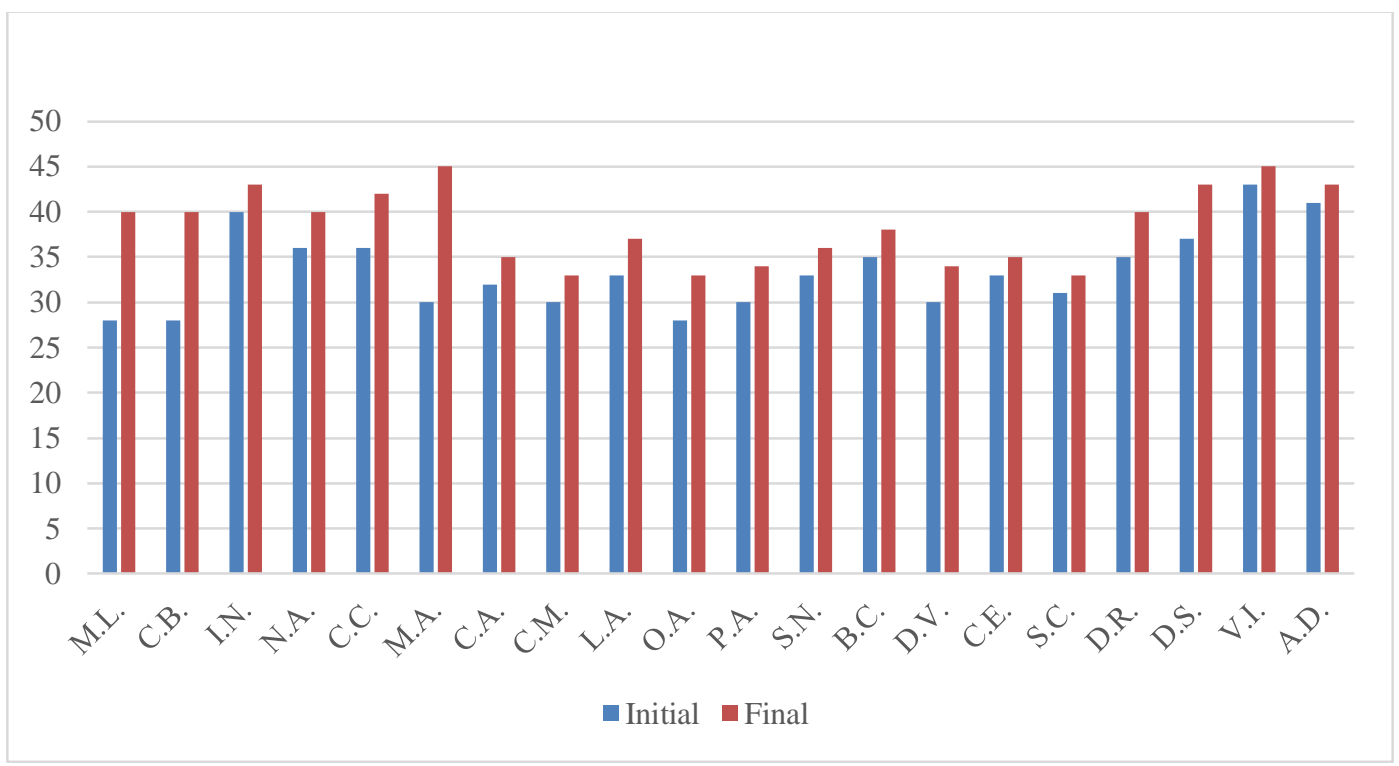

Figure 3. Evolution of data recorded in the initial and final tests for the specific indicators of aerobic exercise capacity, maximum oxygen consumption (VO2 max) 
Figure 3 shows the initial and final values recorded by subjects for the specific indicator of aerobic exercise capacity, maximum oxygen consumption.

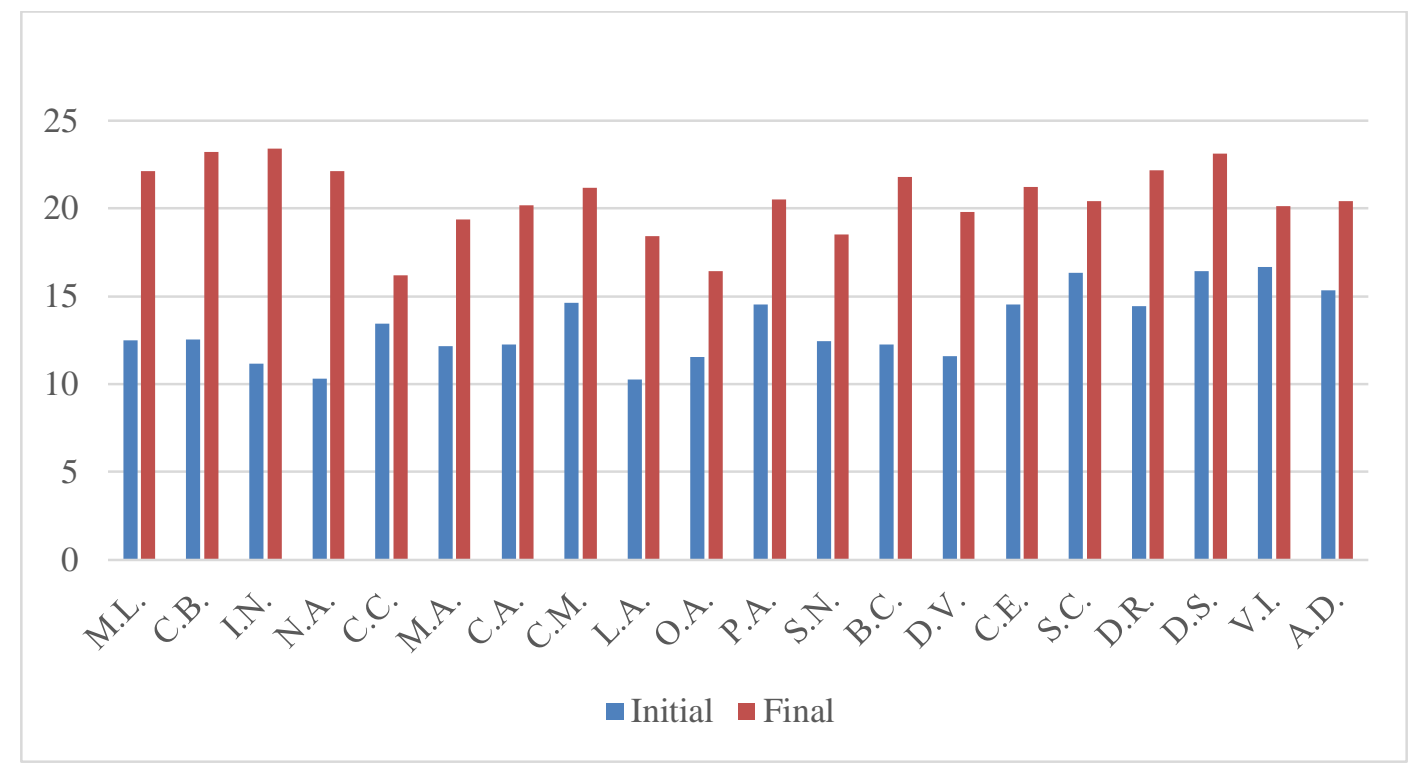

Figure 4. Evolution of data recorded in the initial and final tests for the specific indicators of lactic exercise capacity (LA, mmol/L)

Figure 4 shows the dynamic evolution of lactic acid accumulation in the blood corresponding to the data recorded in the initial and final tests.

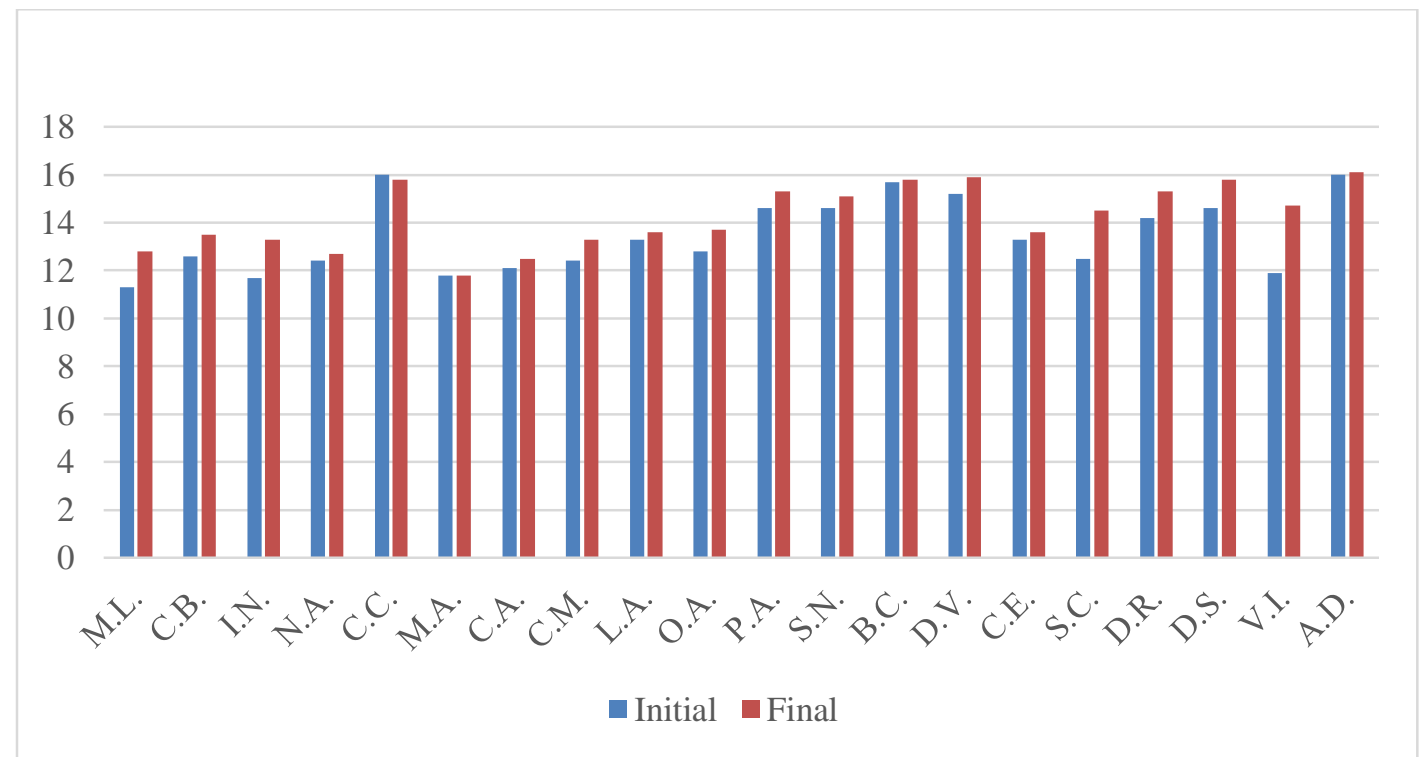

Figure 5. Evolution of data recorded in the initial and final tests for haemoglobin $(\mathrm{g} / \mathrm{dL})$ levels

Figure 5 shows the evolution of haemoglobin levels recorded by the group of subjects. Important increases can be noted at the end of the research, in the conditions of a very close 
dynamic between the values of the two tests. Compared to the dynamics of data evolution for oxygen saturation, there is a close relationship with haemoglobin levels, which ensures a significant increase in adaptative aerobic capacity, and this is demonstrated by the values of maximum oxygen consumption.

\section{Conclusion}

Data recorded in the initial and final assessments highlight a considerable increase in both anaerobic and aerobic exercise capacity during the training macrocycle for elite senior judo athletes.

Thus, the specific indicators of forced vital capacity (FVC) and oxygen saturation (SpO2), with an initial average value of 93.1 and a final average value of 97.4, recorded an increase in all statistical indicators, but also a homogenisation of values as a result of centralised athletic training. At the end of the research, there is a decrease in the values of statistical indicators for standard deviation and STDVP variation, from an initial value of 2.7 to a final value of 1.4. The homogeneity of the results increases by the decrease of variation (VAR) from the initial value of 7.8 to the final value of 2.2. The increase in oxygen saturation recorded at the end of the research supports the adaptation to high-intensity effort, which is demonstrated by the simultaneous increase in haemoglobin levels. We can see that the need for oxygen causes increasingly important adaptations of the respiratory and circulatory systems. However, aerobic capacity, through the values recorded for oxygen consumption (VO2), demonstrates an average level of development compared to the results recorded by high-performance judo athletes (Schumann \& Rønnestad, 2019). Oxygen consumption (VO2) increases from an initial average value of 33.4 to a final average value of 38.5. Increases are recorded for the entire group of subjects by the decrease of variation (VAR) from the initial value of 18.3 to the final value of 16.5 . The values obtained in the spirometry test by determining forced vital capacity (FVC) and digitised pulse oximetry reveal normal vital capacity, with minor increases in the final test, from an initial average value of 93.1 to a final average value of 97.3. Haemoglobin values show increases in the final assessment, from an initial average value of 13.4 to a final average value of 14.2 , with a tendency to reach maximum values, being correlated with the values recorded for oxygen saturation (SpO2 - 97.3). Increases in haemoglobin values for the entire group of subjects are also demonstrated by the variation (VAR) values, from initial average values of 12.6 to final average values of 13.7. Increases in haemoglobin levels and oxygen saturation at the end of the research lead to increases in adaptive aerobic capacity (VO2 max). The increased need for oxygen, the oxygen debt at the end of the combat rounds is caused by the high amount of lactic acid accumulated during the fight. For recovery after exercise, under the effect of high-intensity effort, the judo athlete adapts by increasing respiratory efficiency and optimising oxygen saturation and haemoglobin levels. The amount of lactic acid in the blood, through the average values recorded in the two tests (LA, mmol/L), namely 13.2 in the initial test and 15.8 in the final test, demonstrates increases after the combat rounds due to both maximal intensities of the fight-specific effort and judo training, with a high complexity of motor actions. The values of statistical indicators for the evolution of lactic acid accumulation in the blood show the 
maintenance of high values for the entire group of subjects, which is demonstrated by the data recorded for variation (VAR), from the initial value of 1.8 to the final value of 1.9 .

The values recorded by us in the final assessment are consistent with the values obtained by most authors who conducted similar studies (Franchini et al., 2013). Lactic acid accumulation and the importance of lactacidaemia are justified by the numerous specific motor actions performed based on plyometric contractions with moments of isometry, which leads to predominantly anaerobic effort with lactic acid accumulation due to working in apnoea. These motor actions based on anaerobic energogenesis are present throughout the fight, during both the standing stance and ground fighting. The technical combat model in relation to the weight division can significantly influence the type of adaptive capacity and the coach's intervention through appropriate means and methods.

The assessment of specific indicators by the data recorded in the initial and final tests answers the research question according to which high-intensity effort during the combat rounds leads to adaptations related to an increase in oxygen saturation and maximum oxygen consumption. The comparative analysis of the relationship between the data recorded for maximum oxygen consumption (VO2) and excess lactic acid accumulation (LA, mm/L) highlights the increased oxygen consumption in the post-lactic acid accumulation phases. Increased amounts of oxygen are needed for post-exercise recovery due to the progressively higher amount of lactic acid accumulated simultaneously with advancing in the combat rounds during training or competition.

The recorded data demonstrate the increased adaptation of the research subjects to anaerobic alactic and lactic exercise, with an average level of adaptation to aerobic effort. This significant trend in the data collected from assessing the characteristics of performance capacity, with dominant increases in anaerobic lactic exercise capacity and average values of aerobic capacity, demonstrates profound alterations in the training concept of both specialists and judo athletes aimed at avoiding unnecessary time and energy consumption by means of efficient training adapted to elite competition demands.

The assessment of specific factors regarding exercise capacity in judo allows the coach and athletes to make the transition towards the use of modern methods that are increasingly closer to the competitive activity. During the training periods, the monitoring of adaptive changes allows both the coach and athletes to intervene on the training means and methods for the optimisation of demands. Monitoring the specific factors of exercise capacity contributes to optimising the volume-intensity relationship during training in order to reach the sports shape. The methods for assessing adaptive anaerobic and aerobic exercise capacity demonstrate the very important relationship between effort and recovery, aerobic capacity helping judo athletes to recover after high-intensity anaerobic lactic exercise (Abernethy et al., 1990).

The data presented by us highlight the importance of anaerobic lactic exercise in judo effort, but also the implications of specific adaptive effects on physical training as part of overall training, thus contributing to optimal scheduling and planning of both the training activity and participation in competition.

The analysis of specific adaptive factors presented by us is based on the described methods and needs further completions through research on their relationship with the 
technical, tactical and psychophysical model in order to achieve a comprehensive analysis of the specific demands for each performance category.

\section{References}

Abernethy, P. J., Thayer, R., \& Taylor, A. W. (1990). Acute and chronic responses of skeletal muscle to endurance and sprint exercise. Sports Medicine, 10(6), 365-389. https://doi.org/10.2165/00007256-199010060-00004

Artioli, G. G., Bertuzzi, R. C., Roschel, H., Mendes, S. H., Lancha, Jr., A. H., \& Franchini, E. (2012). Determining the contribution of the energy systems during exercise. Journal of Visualized Experiments, 61: 3413. https://dx.doi.org/10.3791\%2F3413

Beneke, R., Pollmann, C., Bleif, I., Leithauser, R., \& Hutler, M. (2002). How anaerobic is the Wingate Anaerobic Test for humans? European Journal of Applied Physiology, 87, 388-392. https://doi.org/10.1007/s00421-002-0622-4

Farzaneh Hesari, A., Mirzaei, B., Mahdavi Ortakand, S., Rabienejad, A., P. T., \& Nikolaïdis, P. T. (2014). Relationship between aerobic and anaerobic power, and Special Judo Fitness Test (SJFT) in elite Iranian male judokas. Apunts. Medicina de l'Esport, 49(181), 25-29. https://doi.org/10.1016/j.apunts.2013.07.005

Franchini, E., Artioli, G. G., \& Brito, C. J. (2013). Judo combat: Time-motion analysis and physiology. International Journal of Performance Analysis in Sport, 13(3), 624-641. https://doi.org/10.1080/24748668.2013.11868676

Franchini, E., Schwartz, J., \& Yuri Takito, M. (2018). Maximal isometric handgrip strength: Comparison between weight categories and classificatory table for adult judo athletes. Journal of Exercise Rehabilitation, 14(6), 968-973. https://doi.org/10.12965/jer.1836396.198

Hantău, I., \& Bocioacă, L. (1998). Antrenamentul în judo. Pregătirea fizică şi tehnică [Judo training. Physical and technical preparation]. Pitești: Editura Universității din Pitești.

Imamura, R., Iteya, M., Hreljac, A., \& Escamilla R. (2007). A kinematic comparison of the judo throw Harai-Goshi during competitive and non-competitive conditions. Journal of Sports Science and Medicine, 6(CSSI-2), 15-22. https://www.jssm.org/combat/2/4/v6combat2-4.pdf

Murărețu, D. C., Petre, R. L., \& Teodoru, M. D. (2016). Objectifying the execution times of weightlifting athletes - Clean and jerk event. In I. Roceanu (Ed.), The European Proceedings of the 12th International Scientific Conference "eLearning and Software for Education” (Vol. 1: eLearning Vision 2020, pp. 378-383). Bucharest: Carol I National Defence University Publishing House. DOI: 10.12753/2066-026X-16-233

MYCO Instrumentation, Inc. (2014). Sysmex XT 4000i hematology analyzer. https://www.myco-instrumentation.com/equipments/sysmex-xt-4000i/

Norman, L. (2015). The coaching needs of high-performance female athletes within the coach-athlete dyad. International Sport Coaching Journal, 2(1), 15-28. https://doi.org/10.1123/iscj.2013-0037

Perez, L. L. (2013). Office spirometry. Osteopathic Family Physician, 5(2), 65-69. https://doi.org/10.1016/j.osfp.2012.09.003

Sale, D. G., McDougall, J. D., Jacobs, I., \& Garner, S. (1990). Interaction between concurrent strength and endurance training. Journal of Applied Physiology, 68(1), 260-270. https://doi.org/10.1152/jappl.1990.68.1.260

Schumann, M. S., \& Rønnestad, B. R. (Eds.). (2019). Concurrent aerobic and strength training. Springer. http://doi.org/10.1007/978-3-319-75547-2 